\title{
La contribución de la política de información y comunicación al desarrollo democrático de la Unión Europea
}

\author{
Yolanda Martín González \\ Universidad de Salamanca (España)
}

\section{Resumen}

Se analiza el papel que juega la política de información y comunicación eurocomunitaria (PIC) en el desarrollo democrático de la Unión. Para ello, se toman como referencia las distintas iniciativas en materia de e-información y e-comunicación puestas en marcha por la Comunidad con fin el convertirse en una administración diáfana capaz de generar la confianza de sus ciudadanos. El periodo a analizar comprende los años que discurren entre la firma del Tratado de Maastricht (1992), en el que se oficializa la obligatoriedad de la transparencia informativa en el quehacer comunitario, y el periodo actual, umbral del mayor proceso de ampliación realizado nunca en la Unión a países de la Europa mediterránea, báltica, central y oriental. Para realizar el estudio, se examina, por un lado, la literatura existente sobre los procesos informativos y comunicativos puestos en marcha en la Europa común; por otro, los distintos mecanismos digitales desarrollados por la administración europea vigentes en la actualidad. A partir de ello, se establece una comparativa entre el desarrollo teórico de la PIC y la puesta en práctica de la misma. Por último, se consideran las distintas estadísticas elaboradas por la propia Comunidad sobre las consultas efectuadas por la ciudadanía a sus distintas páginas web con el fin de sopesar el nivel de éxito o fracaso de las iniciativas en materia de e-información, e-documentación y e-comunicación. Las conclusiones obtenidas demuestran cómo la PIC está contribuyendo, sin duda alguna, al conocimiento, la consolidación y, sobre todo, la democratización de la Unión Europea.

Palabras clave: e-información. e-comunicación. Unión Europea. Política de información y comunicación.

\section{Abstract}

The role that the European information and communication policy plays in the democratic development of the European Union is analyzed. The studied period includes the years that run between the signature of the Treaty on European Union (1992) — which makes official the obligatory nature of informative transparency

Scire. 11 : 2 (sep.-dic. 2005) 197-204. ISSN 1135-3761. 
in the EU administration - and the present period, threshold of the greatest expansion process of the Union. The gap between theory and the different digital mechanisms developed by the European administration is underlined. Also, the different statistics elaborated by the EU websites on citizens' searchers are studied with the purpose of hefting the level of success or failure of the initiatives regarding e-information, e-documentation and e-communication. The conclusions demonstrate how the European Information and Communication Policy is contributing, with no doubt, to the knowledge, consolidation and democratization of the European Union.

Keywords: e-information. e-communication. European Union. Information and communication policy.

\section{Introducción}

A la hora de hablar sobre la influencia que la política de información y comunicación (PIC) ejerce en el proceso democratizador de la Unión Europea debemos destacar de manera especial el papel que juegan los Consejos Europeos de Birmingham (1992), Edimburgo (1992) y Copenhague (1993) y, sobre todo, el Tratado de Maastricht, al servir como introductores de los conceptos de transparencia y de acceso público a la documentación institucional en el glosario eurocomunitario. Hemos de destacar también los reveses sufridos por la Comunidad en las últimas elecciones al Parlamento Europeo — concretamente las celebradas en 1999 y 2004-, donde se asiste a la más baja participación ciudadana de la historia de la integración y, por supuesto, la no ratificación danesa e irlandesa al último tratado aprobado. Ambos acontecimientos ponen de manifiesto el euroescepticismo imperante entre la población o, lo que es igual, la indiferencia de la opinión pública ante lo que acontece en Bruselas.

La decisión de mantener a la ciudadanía lo más informada posible sobre las decisiones tomadas a nivel comunitario surge de la concienciación, por parte de las autoridades europeas, del distanciamiento existente entre la Unión y sus ciudadanos. Dicho distanciamiento se entiende como un importante hándicap para el buen desarrollo de una entidad supranacional que, por lo general, resulta poco visible y a veces incluso incomprensible para gran parte de su población. Con la puesta en marcha de dispositivos difusores de información, la Comunidad pretende potenciar un espíritu de pertenencia a Europa que sirva como base para la creación de una conciencia europeísta.

Por otra parte, se han activado mecanismos que permiten no solo dirigir el flujo informativo de Europa a los ciudadanos, sino también de estos a la entidad eurocomunitaria, ofreciendo la posibilidad de conocer, en todo momento, cuál es la opinión de la ciudadanía sobre las diversas políticas llevadas a cabo por Bruselas. Esto es, mantener una especie de diálogo — en su mayor parte virtual— entre ambas par- 
tes, lo que, de verdad, contribuye al desarrollo democrático de la Unión. En este sentido, no podemos olvidar que durante muchos años se ha denunciado el déficit democrático que impregnaba la labor europeísta y que parecía tener su base en un significativo déficit informativo.

Por todas estas razones, la política de información y comunicación ha hecho posible que Europa abriera sus puertas mostrándose más transparente y comprensible a sus ciudadanos, especialmente en los diez últimos años, desde la firma del Tratado de Maastricht en 1992 hasta el proceso de ampliación efectuado hace escasamente unos meses. La utilización de las nuevas tecnologías ha contribuido enormemente a la consecución del objetivo aperturista eurocomunitario, ya que el servidor oficial de la Unión Europea, EUROPA, se ha erigido como la fuente de información más actualizada y fiable sobre la Comunidad y también como instrumento de comunicación por antonomasia.

La facilidad con la que, a través de EUROPA, el ciudadano puede obtener información sobre aquellos aspectos que más le interesen, expresar su opinión sobre los temas más candentes del panorama eurocomunitario o incluso realizar transacciones burocráticas a través de la Red ha permitido que la Unión esté realmente al alcance de su mano.

\section{La Europa de la información y la comunicación}

Durante años la ciudadanía europea ha denunciado la falta de transparencia en la ejecución de las políticas y actividades comunitarias. La opacidad ha sido, además de la nota característica de la labor desarrollada por la Comunidad, la causa del creciente distanciamiento entre esta y la opinión pública.

Con el Tratado de Maastricht se quiere, por vez primera, poner fin a esta brecha al formularse una serie de prerrogativas legales que obliguen a la transparencia y faciliten el acceso público a los documentos eurocomunitarios. Los Tratados de Ámsterdam (1996) y Niza (en vigor desde el 1 de febrero de 2003) reafirmarán y ampliarán lo prescrito en Maastricht sirviendo de base jurídica de numerosas iniciativas en materia de información, pero sobre todo en materia de comunicación. Ante tal panorama cambiante, las instituciones se ven, como es lógico, salpicadas por esta nueva mentalidad y comienzan a trabajar, en un principio de forma separada, en el desarrollo y puesta en práctica de su propia política de información y comunicación. No obstante, en el año 2001, la Comisión manifiesta la necesidad de trabajar de forma cooperativa y hace pública una comunicación al Consejo, al Parlamento Europeo, al Comité Económico y Social y al Comité de las Regiones, referente a un nuevo marco para la cooperación en actividades relativas a la política de información y comunicación de la Unión Europea. Este documento es, sin duda alguna, fruto de un conjunto de iniciativas que surgen a raíz de la firma del Tratado holandés y que se han ido desarrollando a lo largo de los años noventa.

Scire. 11 : 2 (sep.-dic. 2005) 197-204. ISSN 1135-3761. 
Por otra parte, la comunicación de la Comisión es fruto también del deseo eurocomunitario de erradicar el déficit informativo que inunda la mayor parte de sus actividades institucionales y que constituye el germen del déficit democrático. Buena prueba de ello es el aún elevado número de reclamaciones que por falta o denegación de información presentan los ciudadanos residentes en la Vieja Europa ante el Defensor del Pueblo europeo. La importancia otorgada a aspectos económicos, jurídicos y políticos ha hecho que las autoridades eurocomunitarias descuidaran sus relaciones con los ciudadanos de modo que, hasta prácticamente la última década, la Unión funcionaba "de espaldas" a su ciudadanía. Sin embargo, circunstancias tales como la baja participación en las elecciones europeas y las negativas danesas e irlandesa a la ratificación de los últimos tratados hicieron reaccionar a los entes dirigentes de la Comunidad, temerosos de que el euroescepticismo se apoderara de la opinión pública. La primera institución que intentó paliar la deficiencia informativa existente fue el Parlamento Europeo, seguido de la Comisión. Ambas fueron las que más rápidamente adoptaron medidas — no solo en el plano teórico, sino también en el práctico— dirigidas a eliminar las barreras surgidas entre la Comunidad y sus ciudadanos pero, sobre todo, a fomentar el espíritu europeísta entre la opinión pública.

De esta forma se va esbozando lo que se ha dado en denominar la Europa de la información. Una Europa que utiliza la información y la comunicación como instrumentos esenciales para engendrar un sentimiento de pertenencia a una entidad supranacional, esto es, para crear una conciencia europea y con ella al homo europeus. Y es en este contexto donde surge el nuevo marco para la cooperación en actividades referentes a la PIC europea.

\section{Un nuevo marco para la cooperación en materia de información y comunicación}

A través de la mencionada comunicación, remitida por la Comisión, sobre un nuevo marco para la cooperación en actividades referentes a la política de información y comunicación de la Unión Europea al resto de instituciones comunitarias, el ejecutivo europeo insiste en la necesidad de trabajar de manera cooperativa entre las distintas instituciones eliminando cualquier síntoma de parcialidad y confusión en la información que la Comunidad ofrece a su ciudadanía. Para conseguirlo propone, en primer lugar, establecer un marco instrumental (definir, compartir y reunir las diversas herramientas); en segundo lugar, establecer acuerdos de asociación a distintos niveles (interinstitucional, nacional, regional y local); y, en tercer lugar, desarrollar un diálogo apropiado con el público proporcionándole acceso a información correcta, transmitiéndole mensajes claros y precisos, es decir, siendo activo y no reactivo. Asimismo se insta a enmarcar todas estas iniciativas 
en una política de información moderna, fiable y eficiente que esté en la línea marcada por Maastricht en cuanto a transparencia y accesibilidad documental.

Todas las actividades cooperativas desarrolladas, en principio por la Comisión y el Parlamento, en materia de información son coordinadas y posteriormente evaluadas, por el Grupo Interinstitucional sobre Información (GII). Este grupo es el que, a nivel político, se encarga de que la PIC logre cumplir su principal objetivo, esto es, acercar Europa al ciudadano de modo que este la sienta cercana y, sobre todo, comprensible, para lo que se requieren estructuras sencillas y sin burocracia. En este sentido las nuevas tecnologías proporcionan indudables ventajas para alcanzar los objetivos comunitarios, especialmente en cuanto a que la ciudadanía puede acceder directamente a un conjunto importante de información sin necesidad de desplazarse de su casa o de su lugar de trabajo.

Además es importante que el público participe en los debates, en las discusiones que se están planteando en la Unión, puesto que esa participación va a contribuir al acercamiento de la sociedad a la labor eurocomunitaria. Así lo entiende la Comunidad y así lo lleva poniendo en práctica durante los últimos cinco años, en los que ha reclamado encarecidamente la participación ciudadana en cuestiones como, por ejemplo, el debate sobre el futuro de Europa o el proceso de ampliación. Incluso se ha permitido la realización de ciertas operaciones administrativas como, por ejemplo, la posibilidad de votación en línea puesta en marcha por la Presidencia griega: eVote (1).

Igualmente, la Unión ha hecho un notable esfuerzo para que la información transmitida se adapte siempre a las características del público al que va dirigida, para lo cual se hace necesario distinguir entre tres tipos distintos de destinatarios y, por tanto, tres tipos distintos de información: general, especializada y para la prensa. La primera va dirigida al público en general. Es una información sencilla y clara sobre la Unión, sus instituciones, su funcionamiento y sus actividades. En este grupo destaca de manera especial la información relativa a los derechos y oportunidades de los eurociudadanos, así como la destinada a grupos de interés especial como son los jóvenes y las mujeres. La información especializada presenta un carácter más puntual y más pormenorizado. Se dirige a grupos específicos interesados en aspectos muy concretos de las actividades acometidas por la Unión o alguna de sus instituciones. La información periodística constituye un importante grupo informativo ya que una inmensa mayoría de europeos tienen noticia de lo que acontece en Europa gracias a estos medios. Por esta razón la Unión, desde sus orígenes, ha insistido en poner en marcha mecanismos informativos especialmente diseñados para el desarrollo de esta actividad comunicativa. De hecho, prácticamente todas las instituciones cuentan con servicios encargados de elaborar, gestionar, organizar, seleccionar y difundir la información. Así, la Comisión cuenta con la DG de Prensa y Comunicación (DG PRESS) y el Parlamento con la DG de InformaScire. 11 : 2 (sep.-dic. 2005) 197-204. ISSN 1135-3761. 
ción y Relaciones Públicas (DG III). El trabajo llevado a cabo por estos servicios es fundamental para el buen desarrollo de la política de información y comunicación europea, puesto que ellos son los responsables de que la información sea objetiva, esté actualizada y sea comprensible para todos. En este sentido cabe señalar la necesidad de que los datos y los documentos se hallen traducidos a los 20 idiomas oficiales de la Unión.

Con el fin de llegar hasta el último recodo de su vasto territorio geográfico, la Unión ha optado igualmente por mantener un cierto grado de descentralización en la difusión de su información. De ahí el importante papel que juegan tanto la red de enlaces de información dispuesta por la Comunidad en todos los Estados de la Unión e incluso en terceros países como los distintos recursos informativos electrónicos en general. En concreto, la red de enlaces de información, de la que forman parte las Oficinas de Representación, los Info Points, los Carrefours, los euro Info Centers, los Centros de Documentación Europea, los centros EPICOR y las Eurobibliotecas, actúa como un importante instrumento difusor en esa telaraña informativa al tiempo que juega un papel intermediario fundamental entre la Unión y la opinión pública. Además, estos centros proveedores de información presentan como rasgo característico el que se hallan físicamente ubicados de manera muy próxima al ciudadano, lo que hace imprescindible que colaboren estrechamente con las entidades locales.

No obstante, las actividades desarrolladas por estas unidades se han visto alteradas por la introducción de las nuevas tecnologías en el ámbito informativo de la Unión. Estos nuevos servicios electrónicos presentan una serie de ventajas, especialmente en lo que atañe a la rapidez con la que se accede a la información y la documentación eurocomunitaria. El hecho de que el ciudadano pueda localizar un determinado dato o documento que le interese desde su propio ordenador o pueda estar puntualmente informado de lo que acontece en las distintas instituciones y órganos ha supuesto un notable avance. Asimismo, se contribuye a democratizar la Vieja Europa al permitir la participación electrónica de la ciudadanía en los acontecimientos más relevantes de la Comunidad pese a que exista una clara brecha digital. En este sentido, desde hace varios años, se organizan regularmente distintos foros electrónicos de intercambio. El objetivo consiste en permitir que, durante un periodo determinado de tiempo, los ciudadanos aporten sus ideas y opiniones sobre temas relevantes que afectan al desarrollo de la Unión. El foro es multilingüe y permite a cada uno ver la todas las intervenciones y, en su caso, las respuestas aportadas por los participantes. Se organizan debates, en particular, en el contexto de las iniciativas "Debate sobre el futuro de la Unión Europea" (http://europa.eu.int/futurum/index_es.htm) y “Tu voz en Europa” (http://europa.eu.int/yourvoice/index_es.htm). Estas iniciativas tienen por objeto, respectivamente, asociar a los ciudadanos a un proceso de reflexión e intercambiar ideas sobre lo que es la nueva Europa.

Scire. $11: 2$ (sep.-dic. 2005) 197-204. ISSN 1135-3761. 


\section{Conclusiones}

La política de información y comunicación desarrollada por la Unión contribuye a su conocimiento y consolidación, aunque quizás lo haga a un ritmo menor de lo que esperaban las autoridades europeas. Si bien es cierto que se ha realizado un enorme esfuerzo por poner en marcha dispositivos que contribuyan al establecimiento de flujos informativos y comunicativos entre Bruselas y los ciudadanos, estos siguen mostrando indiferencia o despreocupación sobre lo que acontece en los círculos eurocomunitarios. Sorprende saber que, según las encuestas realizadas por el Eurobarómetro, en la mayor parte de los Estados miembros la opinión pública se muestra favorable a la pertenencia de su país a la Unión, pese a que en los últimos comicios europeos celebrados la participación fue menor del cincuenta por ciento.

La apatía mostrada por el ciudadano ante la actividad política europea parece ser una consecuencia más del desinterés hacia la política en general, pues la tasa de participación en las elecciones nacionales celebradas en los distintos países no dista mucho de la comunitaria. No obstante, en nuestra opinión, la política desarrollada en materia de información y comunicación eurocomunitaria está dando sus frutos y ello se debe en gran medida a la aplicación que se ha hecho de las nuevas tecnologías en este ámbito.

El servidor oficial de la Unión, EUROPA, constituye hoy por hoy uno de los portales más visitados del mundo y una fuente imprescindible de información sobre cualquier aspecto relacionado con el proceso de integración europeo. A través de él el usuario puede obtener información, ya sea general o especializada, expresar su opinión o sus ideas sobre un tema concreto y realizar transacciones administrativas tales como enviar una reclamación al Defensor del Pueblo europeo.

En otro orden de cosas, la cooperación establecida entre las diversas instituciones comunitarias en materia de información y comunicación está también alcanzando su objetivo al acercarse al ciudadano neófito en temas europeos. Los mecanismos dispuestos por ellas contribuyen a estimular los debates sobre cuestiones comunitarias - actuales y futuras-, mejorar la participación del público en el proceso de toma de decisiones y, sobre todo, reforzar el carácter democrático de las instituciones así como la confianza de sus ciudadanos en la Administración europea.

\section{Notas}

(1) Este proyecto se puso en marcha el 10 de febrero de 2003 ofreciendo información en las 11 lenguas oficiales de la Unión, a las que se unieron, el 16 de abril, 8 idiomas más correspondientes a los países candidatos. 


\section{Referencias}

Comisión Europea (1994). Información, comunicación y transparencia. Luxemburgo: Oficina de Publicaciones Oficiales de la Unión Europea, 1994.

Comisión Europea (2001). Un nuevo marco para la cooperación en actividades referentes a la política de información y comunicación de la UE. COM (2001) 354-final.

González Alonso, L. N. (2002). Transparencia y acceso a la información en la Unión Europea. Madrid: COLEX, 2002.

Martín González, Y. (2002). La documentación y los servicios de información del Parlamento Europeo. Gijón: Trea, 2002.

Ros García, J.; López Yepes, J. (1994). Políticas de información y documentación. Madrid: Síntesis, 1994.

Sánchez Martínez, M. (1999). Bases de la política de información y comunicación de la Comunidad Europea. Madrid: Centro de Investigaciones Sociológicas, 1999.

Unión Europea. El portal de la Unión Europea. URL: <http://www.europa.eu.int>. Consultado: 2004-03-01. 